\title{
Transforming Government's Policy-Making Processes
}

Why encouraging more and easier citizen input into policy-making is not enough

\author{
Paul J ohnston \\ Internet Business Solutions Group, Cisco, pauljohn@cisco.com
}

\begin{abstract}
We have seen a lot of very welcome progress in terms of making it easier for citizens to input their views into government policy-making processes. However, governments and citizens are now in a similar situation - after a burst of initial enthusiasm, they are not sure what to do next. Governments have struggled to get the mass participation they would like and where significant participation has occurred, have had difficulty integrating it effectively into existing decisionmaking processes. Citizens have been unsure what to make of this new apparent openness and where they have engaged, have found it hard to know what difference their input made. The solution is to focus on using technology to make existing policy processes more transparent and more participative rather than creating separate e-participation initiatives. The challenge for governments is to open up the whole of the policy process and be prepared to flag up very clearly and explicitly the difference citizen input made. The challenge for e-democracy advocates is to convince policymakers that their ideas can improve the existing policy process rather than simply generating more inputs into it.
\end{abstract}

Keywords: transparency, participation, deliberation, policy-making, empowerment, engagement

Acknowledgement: The views expressed in this paper are the personal views of the author, but he would like to express his gratitude to the many people with whom he has discussed this issue particularly his Cisco colleagues.

A

II around the world governments have embraced the concepts of openness and participation and launched initiatives that have achieved significant citizen involvement. Look at the response Barack Obama got as he sought to involve citizens in his preparations for becoming the 44th President of the United States. One hundred and twenty five thousand people participated in his Citizen's Briefing Book initiative with 44,000 ideas being put forward and 1.4 million votes being cast. $^{1}$ When he gave citizens the chance to ask him a question, 20,000 participants submitted 10,000 questions and cast 1,000,000 votes, while in the second round of the same initiative the response increased with 103,512 people submitting 76,031 questions and casting $4,713,083$ votes. $^{2}$

Barack Obama continued with this approach as president, but it is significant that his open government initiative saw declining rather than increasing popular enthusiasm. Phase One of the Open Government Initiative was a brainstorm undertaken using the IdeaScale tool and elicited more than 900 ideas and 33,000 votes. Phase Two was a discussion on the Office of Science and Technology Policy blog, which attracted more than 1,000 comments in response to 16 topics. Phase Three involved collaborative drafting, using the Mixedlnk tool and produced 305 drafts by 375 authors with 2, 256 people voting on those drafts. ${ }^{3}$ All of this is significant and welcome involvement, but it is not the rising curve one might have wanted to see. Now two years after

\footnotetext{
${ }^{1}$ Bittle, S., Haller, C. \& Kadlec, A. (2009). Promising Practices in Online Engagement. New York: Public Agenda. Retrieved September 7, 2010, from http://www.publicagenda.org/files/pdf/PA_CAPE_Paper3_Promising_Mech2.pdf

2 Lee, J. (2009) Open for Questions Round 2: Response. Retrieved September 15, 2010, from http://change.gov/newsroom/entry/open_for_questions_round_2_response/

${ }^{3}$ Office of Science and Technology Policy, OSTP Blog. http://blog.ostp.gov/category/opengov/
} 
Barack Obama came to power, the enthusiastic hope that he would open up Washington and let citizens really get involved in policy-making seems largely to have disappeared.

If the U.S. federal government is no longer the standard-bearer it once was, there is no lack of countries ready to take up the charge. The United Kingdom saw a change of government in May 2010 and the conservative-liberal democrat coalition has embraced transparency and participation with gusto. The new government was committed to repealing unnecessary laws and regulations, so it created a site where citizens could highlight rules that should be abolished. ${ }^{4}$ It was also determined to cut the UK's spending deficit, so it used a similar platform to allow citizens to suggest ways of saving money. ${ }^{5}$ Indeed, the new government was so keen to involve citizens that it asked Facebook to publicize their initiatives and encourage their users to get involved. ${ }^{6}$

These UK initiatives are typical of efforts by central government, but it is hard to see how they will generate much value either for the government or for the citizen. While the technology costs are relatively low, the government would need to devote a huge amount of effort to considering the tens of thousands of suggestions it has received, if it wanted to take them seriously. Furthermore, it is unlikely that many of the suggestions will be things that no one has thought of before. Some will be facetious (for example, the UK government was encouraged to repeal the third law of thermodynamics ${ }^{7}$ ) and many others will be familiar to the relevant policymaker. Those that do have more potential may be very hard to pick out from the others on the basis of a short written explanation. One suspects therefore that the most likely outcome is that one or two fairly obvious ideas that were stalled in the policy process will be given some extra momentum by the need for the government to show that the participation exercise succeeded. Similarly, from the citizen's point of view, it is hard to see how the exercise can fail to seem one-off and superficial. There is, for example, no commitment on the government's side to tell the individual citizen what happened to their suggestion. Given the number and quality of the other suggestions and the nature of the process, if you were a citizen with the germ of a truly innovative money-saving idea, would you spend a couple of hours thinking about and researching it, so you could input it into the site? If you did decide to take part, aren't you more likely just to input something off the top of your head that even if was potentially worthwhile would be incredibly difficult to identify as worth exploring further?

One way some people have reacted to these enthusiastic, but superficial attempts to involve citizens is to create other tools that seek to put power more directly in the hands of the people. One example of this phenomenon is pressure in many countries to create e-petition systems at local, regional or national level. Others have developed more elaborate forms of virtual direct democracy. For example, in the United States Jim Gilliam created WhiteHouse 2, which is a platform designed to allow citizens to set the government's priorities and collaborate on designing policy. ${ }^{8}$ Similarly, in the United Kingdom David Woods created the Virtual Parliament, a not-for-profit website where citizens can vote on policy ideas and suggest their own. ${ }^{9}$ The big problem these sites have is that

\footnotetext{
${ }^{4}$ Your Freedom, HM Government. http://yourfreedom.hmg.gov.ukl

${ }^{5}$ HM Treasury. http://spendingchallenge.hm-treasury.gov.uk/

${ }^{6}$ The collaboration with Facebook was highlighted in a youtube video (Number10gov. (2010). PM and Facebook co-
} founder Mark Zuckerberg. Retrieved September 15, 2010, http://www.youtube.com/watch?v=b5Bbzi7s1Ko), but in practice did not lead to much - there was a short-lived Facebook UK Spending Challenge page that attracted less than 100 fans before being taken down.

${ }^{7}$ jsmithagain. (2010). Reduce disorder by repealing the $3^{\text {rd }}$ Law of Thermodynamics: Why contribution is important. Retrieved September 15, 2010, http://yourfreedom.hmg.gov.uk/restoring-civil-liberties/reduce-disorder-by-repealing-the-3rdlaw-of-thermodynamics

The contributor justified his idea on the following grounds: "This idea will save money, allow people to live longer and help the environment. Repealing the Third Law of Thermodynamics will enable our society to maintain order without the current energy costs that are otherwise required. This will not only save money in these financially stringent times but will also benefit the environment by reducing the energy that is otherwise used to maintain order. In addition, maintaining order in this low cost, environmentally friendly way will prevent the current senseless loss of life that otherwise occurs."

${ }^{8}$ White House 2. http://www.whitehouse2.org/

${ }^{9}$ Virtual Parliament. http://www.virtualparliament.org.uk/policy/ 
due to their disconnect from the real policy-making processes they have difficult generating or sustaining the level of involvement they would need in order to have an influence. WhiteHouse 2 has attracted just over 11,000 members in the two years it has been in existence, while Virtual Parliament has less than 150 users, almost all of whom seem inactive.

Different countries are at different stages in the cycle, but it seems clear that there is a real risk of mutual disenchantment. Citizens (and e-democracy advocates) may feel that governments are not really prepared to cede power and often only engage in participation exercise for PR reasons. Governments may feel that citizens have unrealistic expectations and do not really want to engage with the difficult part of the policy process, which is recognizing that even the best proposal has downsides and will create losers. The e-democracy initiative that secured the most participation ever in the United Kingdom was the petition on the No 10 Downing Street website against roadpricing. One-and-a-half-million people endorsed the petition and sent a clear, but not very helpful message to government. The no-to-road-pricing was not a yes to raising money in other ways or to reducing congestion in other ways or to tackling carbon dioxide emissions in other ways. It was simply a no to something that sounded unpleasant.

In my view the way forward involves focusing much more directly on the policy process as it currently exists. To date the tendency has been to emphasize the new possibilities of involving people and explore ever more innovative and appealing ways of getting citizens interested. While this has produced some successes at a local government level, it has had much less success in relation to central government. Instead, there have been a number of one-off exercises that often create anger when the outputs of the initiatives do not have a significant or clear impact on any decisions. Part of the problem here may be a lack of understanding and reflection about the policy process itself. It is easy to contrast e-democracy with the black box of government decisionmaking, but there is a risk of thinking in terms of caricatures - there are few countries where policy is decided by one or two ivory-towered public servants who have an idea and then implement it without anyone else having much of a say.

Consider how the policy process actually works in a country such as the UK. Far from living in policy vacuum, government faces a constant barrage of stakeholders telling it what it should do. These may be think tanks, academics or journalists or they could be individual companies, industry associations, NGOs or unions. In addition, there is the mass of commitments a newly elected government brings into office with it. Then as the government starts to indicate what it might do, there will be further bursts of activity by these stakeholders plus debate in parliament and in the media. Now, of course, the individual citizen may feel very remote from all of this, but in my view it is neither realistic nor desirable to think that all of this might be bracketed off and replaced by some perfect but yet to be invented e-democratic platform. Instead I think we should work to make the existing policy process more transparent and use that increased transparency as a basis for increased citizen participation at all stages of the policy process and not just at the start. What might that involve?

\section{Increasing the Transparency of the Policy Process}

The starting point should surely be much more transparency about who ministers and policymakers are meeting and what input they receive from the people and organizations they already meet. It is hard to see why any organization that makes a submission to a department on a policy matter should object to that submission being made publically available, and it is certainly important and useful for citizens to know who is making what kind of input. Once such input was publically available in a user-friendly way, this would create a natural space for citizen involvement in terms of assessing, commenting on and rating the points made in the submission. Civil servants could get involved in that debate, but even if they did not, they might gain either because weaknesses in the argument being made would be highlighted or because they would get an indication of likely reaction to the policy move being suggested. Arguably, one could take this further and make public as much individual input into the policy process as possible, e.g. citizen 
letters/emails/faxes to ministers. ${ }^{10}$ Publishing this input may encourage the department to analyze and monitor the trends in the input it receives as well as trends in the online reaction to this input. From the department's point of view, it may also be helpful to highlight the conflicting pressures it is coming under and so encourage stakeholders to take more balanced positions.

Publishing input on policy issues from organizations as a matter of standard practice would seem hard to argue against. The next step - making public which external stakeholders a minister (or policymaker) is meeting and the subject matter of the meeting - is potentially slightly more sensitive, but it should not be too difficult to devise an approach that meets any reasonable concerns either party might have. At least initially the public details might be limited to attendees and a one-sentence description of each of the topics discussed. There could also be scope for excluding meetings from publication (or delaying publication etc) if the very occurrence of the meeting was commercially or politically sensitive. Moving in this direction would enable citizens to understand who was trying to influence ministers and on what issues and would, of course, provide a further opportunity for citizens to input into the process. They might, for example, highlight other groups policymakers should consider meeting or flag up aspects of the organisation's position on the particular topic that the department might want to explore more deeply.

Moves in this direction offer two kinds of benefit. On the one hand, they increase the scrutiny that inputs into the policy-making process receive. Policy-makers may be pointed to counterarguments or evidence balancing or undermining the arguments put to them. Their doubts about a particular claim may be reinforced or they might be led to reconsider their assumption that something was practical (or impractical) when they discover that many people take a different view. On the other hand, increased transparency may help policymakers by ensuring that those inputting ideas to government have a clearer sense of the complex debate they are contributing to. Transparency will not eliminate the complexities and conflicts of policy-making, but allowing a more open debate can at least help people understand that failure to take up a particular suggestion is generally not just a matter of the government stupidly not wanting to listen.

One striking point about the central government policy process from a citizen point of view is that it is actually quite difficult to get a clear picture of what is going on at any particular point in time. Take a simple UK example, the license fee that every owner of a UK-based functioning television set has to pay to fund the BBC. This is a policy issue that almost always on the agenda - should it be abolished? Could the fee be reduced or increases limited? Should the scope of operations of the BBC be change to reduce the funding needed? Should other broadcasters have the chance to share in some of the money raised? Most UK citizens probably have a view on some or all of these issues, but if they wanted to find out which issues were currently under active consideration and what the likely next steps were, there is no obvious place for them to find this information. They could go to the website of the relevant department and if the minister has recently spoken on the topic they are interested in, they might get some idea of what is going on. However, if they are new to the issue, they may find even a relevant ministerial speech hard to follow insofar as it is likely to be primarily addressed to people already familiar with the issue. So at present in most countries citizens have no way of knowing what is "live" within the policy process and what is not. Even in areas where they know the government is planning action, getting even a rough idea of what the next step might be and when it is likely may be difficult or even impossible. No wonder government policy-making is seen as a black box.

Changing that might seem a mammoth task and in the current context where many governments are looking to cut budgets and reduce staff, it might seem unrealistic to expect a new initiative to give citizens a clear picture of a government's huge and constantly changing policy agenda. But the example of Wikipedia suggests a possible way forward - why not treat this challenge as an ideal opportunity for co-production? Why not aim to create a process where most of the work is

\footnotetext{
${ }^{10}$ Obviously one would need to be sensitive to privacy issues here. Since someone writing to a minister or department might not be expecting their communication to be published, it might be reasonable both to anonymise all input before it was published and to exclude communications that related to specific cases.
} 
done by citizen volunteers rather than by civil servants? This "Policypedia" tool would feature clear summaries on the history, background and next steps for the most important policies in a particular area. The initial framework and ultimate editorial control might be a matter for government, but citizens could be allowed to register and update and enrich the tool with their editorial rights increasing on the basis of the proven impartiality and quality of their contributions. In the first instance coverage might be limited to an administration's key policies, but once a site/tool, a process and a brand had been established, there could be scope for making it increasingly comprehensive. ${ }^{11}$

\section{Increasing the Impact of Citizen Input}

So far, I have focused on opening up the policy black box, but the other big issue is increasing the impact that citizen input has - unless citizens believe that their involvement is making a difference participation is unlikely to continue, let alone, increase. The way government consultation currently works actually makes it very difficult for citizen input to have a clear impact. Typically, a formal consultation gives citizens a brief opportunity to offer comments in response to a limited set of questions with the consultation document itself usually doing its best to hide the difficult policy choices that are being made and so promote a particular way forward as the only sensible choice. When the consultation period ends, the policymakers are hit by a wave of textual comments, some disagreeing with the government's policy objectives, some challenging their analysis of the problem, some suggesting new measures incompatible with what the government is proposing, some arguing for adjustments to the current plans. Sometimes the comments are made by organizations that claim to represent hundreds of thousands of citizens; sometimes they express the views of individuals. Somehow all of this is summarized and it then feeds into the policy process, but it is not surprising that the impact is often unclear, particularly in a media and political culture where any clear acknowledgement of change risks being labeled a humiliating uturn.

There are a number of ways this situation could be changed. One is by opening up the policy process in the way we have already discussed, so that citizen input does not come in short bursts but is spread over the whole process. Another is developing new and better tools for aggregating citizen input. We need to move away from textual comment as the default form of contribution towards tools that give a clear picture of what everyone responding to the consultation thought. The reason aggregation is key is that it increases the chance that the input will be listened to and have an impact. So far, most of the innovation around government consultation has been about making the process more attractive and more engaging for citizens; now we also need to innovate about making the input more compelling and useable by policymakers.

One possible source of inspiration is the world of policy-mapping where some quite sophisticated tools have been developed. ${ }^{12}$ So far, these tools have focused on capturing the logic of a complex debate, but simplified versions could be used to give clear aggregated feedback on where citizens stand in relation to a particular policy. For example, you could create a tool that was built around a simple template of a policy argument. The tool would then provide an aggregated picture of whether citizens agreed with this argument and indicate at what points they disagreed. For example, the template might look something like this:

\footnotetext{
${ }^{11}$ Not surprisingly, this sort of thing has in fact been tried already (see: Wikia. http://policy.wikia.com/wiki/Main Page) but as this example shows, without the support and involvement of government it is hard to come up with a tool that secures in the aim of making it easy for citizens to see what is going on within the policy machine.

${ }^{12}$ See, for example: debategraph, the global debate map. http://debategraph.org/
} 
1. Agree with government analysis of problem and objectives

a. Broadly agree with main aspects of proposed response

i. Think some proposals could be improved

1. Name proposal(s)

a. Describe improvement

ii. Think additional measures would help

1. Name measure

a. Explain why it would help

b. Disagree significantly with proposed response

i. Think key measure is missing

1. Describe measure

ii. Think one or more proposal is flawed

1. Explain which proposal you disagree with

a. Explain why

2. Disagree with government analysis of problem and objectives

a. Disagree with analysis of problem

i. Explain disagreement

b. Disagree with objectives

i. Explain suggested alternative objectives

The tool (or a related one) could also be used to rate individual aspects of the policy package in terms of relative importance, difficulty of implementation etc. This sort of tool would give a clear picture of where citizens stand in relation to the government proposal. It would highlight very clearly where the government's view was supported and where it was not. Of course, from the government's point of view this might seem a mixed blessing - no policymaker wants to discover that $90 \%$ of respondents are unconvinced of the merits of a particular proposal, but at least aggregation means red flags are unmistakable and government can either change course or check carefully the basis of its position and work on improving the way it makes its case.

There are many other tools government might experiment with to aggregate citizen input. For example, it would be useful to create a tool that allowed citizens to design a policy package in relation to a particular issue within a set of constraints. The department could indicate how much money and how much time/effort/political capital it had to spend on a particular issue. It would then list the measures it was considering in a particular area and assign each a financial cost and an implementation effort cost (a number capturing the time/effort/political capital to implement). Citizens would then be invited to indicate their preferred package within the indicated constraints. Potentially, use of the tool could be in two phases with the first phase involving debate and discussion about assigning financial and implementation costs to particular measures and the second phase involving choosing the preferred package. The first phase could allow citizens to add additional measures to those proposed by the government, but the government would need to have the ultimate decision on assigning a financial and implementation cost to any proposal (and that might include excluding a proposal not because it was literally impossible, but because the financial or implementation costs exceeded what was available). This tool would help aggregate input from citizens in a clear way and would also help promote a policy discussion that recognized the constraints governments face. Like the policy template tool, it would also create better opportunities for discussion between citizens and between citizens and policymakers.

The above suggestions involve aggregating input from an unlimited number of citizens with the demands on the citizen's time not being markedly different from traditional forms of consultation. A different way of trying to give citizen input additional impact would be to create a transparent citizen policy-assessment forum that would give its verdict on a department's policy proposals and also be able to put its own proposals on the agenda. Citizens with an interest in a particular department would be able to register their interest in being citizen policy advisors. From this group, the department would randomly select a number of citizens to be part of the Assembly for a limited time period (perhaps six months or one year). Once the Assembly was convened, the department would submit all major policy initiatives to the Assembly for debate and consideration. Only 
members of the Assembly would be able to take part in the online debates, but all discussion would be public and would end with a public vote by Assembly members. The Assembly might have the right to vote on the government proposals as a whole or broken down into a number of elements. As well as debating government proposals, each session would also be able to debate and then make a number of proposals to the department. Choice of what proposal to debate would rest with the Assembly, but non-Assembly members might be able to suggest ideas to the Assembly. This type of initiative would give groups of citizens a sustained opportunity to get involved in the work of a department and to influence the policy agenda. From the department's point of view, it would give them an informed group of citizens to interact with over a sustained period of time.

These suggestions are intended to increase the impact of citizen input on the policy process by making that input harder not to respond to. Ultimately, however, if governments are to convince citizens to get involved, they will need to be prepared to recognise very clearly the difference this involvement has made. This would involve highlight what the government was going to do, but is now reconsidering; what it wasn't going to do, but is not considering doing; and ideas that it had ruled out/not thought of that it was now investigating. This would be a major cultural change from government's point of view, but it is a necessary part of increasing citizen participation in the policy process. Initially, it might seem that a government which was prepared on a regular basis to admit that it got things wrong or missed things would undermine the credibility of its policy-making processes. In practice, however, the myth of government omniscience (and the related idea that there are easy choices) is already so tarnished that abandoning it would increase credibility. Indeed, liberating the policy process from the burden of this myth would improve the process itself. If a more open policy process made it more acceptable for ministers to change their minds, this would seem to be an additional benefit. In any event, governments that want more participation must be prepared to grasp the nettle and spell out very clearly how that input has changed what they were going to do.

\section{Conclusion: A Different Way of Making Policy}

This paper is based on a belief that they way governments make policy needs to change radically. It is not just a matter of increasing access to the policy-making process and making participation more attractive to citizens. Rather the whole process needs to be opened up. Moving in the direction suggested by this paper should make the central government policy process easier for citizens to understand and engage with in a more meaningful way. It would also create opportunities for citizens to input their views and ideas at all stages of the policy process rather than just at the start, and it would allow for sustained engagement rather than brief opportunities to contribute to an apparently closed process. From the government perspective, there will be significant challenges in opening up the policy process will (as with any other major cultural change), but it will also bring real benefits. The greatest of these is the potential improvement in the policy process itself. The fact that everything is in the open should promote better behavior and more rigorous, evidence-based argument by all involved. It should also encourage a more disciplined process with clearer differentiation of aims and means and clear articulation of which particular policy proposals are supposed to contribute to which objective and how. Transparency could also help change the context for policy debates. At the moment there is a tacit expectation that governments should be able to come up with policies that radically improve the situation without creating any losers. A more open policy-making process where the conflicts and complexities the government has to deal with were obvious to everyone could be the basis of a more mature dialogue. This would be hugely better both for governments and for citizens. 


\section{About the Author}

Paul Johnston

Leads the European public sector team in Cisco's Internet Business Solutions Group (IBSG). With David Osimo, he launched the Open Declaration on European Public Services that was presented at the $5^{\text {th }}$ Ministerial egovernment Conference in Malmo November 2009. Prior to joining Cisco, he led the local government team at the UK Treasury, where he worked for a succession of Chief Secretaries to the Treasury. As a policy advisor, he shaped the UK government's 2000 housing white paper, helped finalize the UK's market abuse legislation, and played a significant role in three Spending Reviews. 